\title{
CUSTOMER HETEROGENEITY IN THE DEVELOPMENT OF E-LOYALTY
}

\section{ABSTRACT}

Purpose: The purpose of this study is to identify customer-specific differences in a general model of e-loyalty taking into account the existence of unobserved heterogeneity. Specifically, we aim to 1) test for the presence of customer heterogeneity 2) assess the impact of potential bias when there is no control for heterogeneity; 3) analyze the distinct customer segments that emerge from the empirical estimation of the model, and 4) describe the segments by their demographic and psychological characteristics.

Design/methodology/approach: Panel data from a survey of online shoppers is used in a post hoc segmentation method, which will enable us to identify segments, while estimating the parameters by means of structural equation models;

Findings. Three distinct consumer segments emerge. The relative importance of e-loyalty and e-satisfaction is significantly determined by consumers' shopping styles.

Originality/value This study highlights the need to consider unobserved customer heterogeneity when attempting to explain satisfaction and loyalty development processes in the retail context in general, and e-commerce in particular. To our knowledge, this is the first time this approach has been used to analyze the impact of customer heterogeneity on esatisfaction and e-loyalty.

Key words:

Online shopping, e-satisfaction, e-loyalty, latent segmentation

\section{Introduction}

Deep Internet penetration and fast-growing e-commerce have revolutionized customer relationships, and studies predict that, by the year $2017,60 \%$ of total consumer spending in the USA will take place online (Dusto, 2013). The numerous advantages of online shopping, 
such as a wider range and variety of goods, effortless comparison of offers, and immediate access to consumer ratings, make e-commerce highly competitive (Gensler et al., 2012).

Online retailers do not have everything in their favor, however. They also have to deal with potentially much higher customer attraction costs than in the marketplace (Lahuerta Otero et al., 2014). High levels of customer loyalty are also difficult to achieve, due to the lack of interpersonal contact and low switching costs (Valvi and Fragkos, 2012). Reichheld and Schefter (2000), for example, estimate a difference of $20 \%$ to $40 \%$ in the clothing category. Their study shows that online companies need to retain their customers for an average of two to three years, in order to recover acquisition costs, while up to $50 \%$ of their customers may desert before three years are up.

Given the importance of customer loyalty management in traditional retail channels, and in light of the aforementioned factors, online loyalty is obviously a crucial issue in the research on electronic marketing channels. Loyalty is inextricably related to the sustained growth and long-term survival of e-retailers (Anderson and Mittal, 2000, Reichheld et al., 2000, Srinivasan et al., 2002, Zhang et al., 2011). Research is therefore essential to further understanding of its antecedents. This is clearly demonstrated by the proliferation of papers on e-commerce that has appeared since the publication of Srinivasan, et al. (2002) (a search for the term on Google Scholar turns up over 3000 entries) and numerous reviews on the subject (e.g. Yadav and Pavlou, 2014).

The majority of these papers typically assume customer homogeneity in the calibration of e-loyalty models, while ignoring the heterogeneity of consumer characteristics and responses (e.g. Floh and Treiblmaier, 2006, Srinivasan et al., 2002, Kim et al., 2009). This approach may be adequate in the initial stages of the research, but requires improvement if reality is to be accurately reflected and erroneous conclusions avoided (Ansari et al., 2000, Bucklin and Sismeiro, 2003, Jedidi et al., 1997). 
For example, according to the literature on brick-and-mortar stores, the main antecedent of e-loyalty is considered to be satisfaction, and it is widely accepted that higher satisfaction leads to stronger loyalty in the e-customer (e.g. Floh and Treiblmaier, 2006, Kim et al., 2009, Srinivasan et al., 2002). This relationship cannot be extrapolated to all contexts, however. Other antecedents sometimes have more impact (e.g. Balabanis et al., 2006), and the relationship can be weaker, or non-existent among some types of customer (e.g. Anderson and Srinivasan, 2003, Belanche et al., 2012, Souitaris and Balabanis, 2007).

As well as leading to clearer conclusions, the consideration of customer heterogeneity in eloyalty models is also enriching from the marketing manager's perspective, given that marketing effectiveness is greatly increased by the identification of homogeneous consumer subgroups or segments with distinct responses to marketing stimuli (Wedel and Kamakura, 2000).

The conceptual framework section of this paper contains on a review of the research published since 2002, in which some measure of customer heterogeneity is included in the analysis of loyalty. It reveals that the approximations are obtained almost exclusively from $a$ priori segmentations, or by including certain moderators.

Based on all of the above, the overall objective of this paper is to analyze the impact of unobserved customer heterogeneity in the development of e-loyalty. Specifically, we aim to: 1) test for the presence of customer heterogeneity, using a post hoc segmentation method, which will enable us to identify segments, while estimating the parameters by means of structural equation models; 2) assess the impact of potential bias when there is no control for heterogeneity; 3) analyze the distinct customer segments that emerge from the empirical estimation of the model, and 4) describe the segments by their demographic and psychological characteristics. 


\section{Research model and hypotheses}

As advanced in the introduction, the study of customer loyalty is even more relevant in the online than in the traditional context, due to factors such as the lack of face-to-face contact between buyer and seller (Szymanski and Hise, 2000), high customer acquisition costs, and low switching costs (Agrawal et al., 2001, Reichheld and Schefter, 2000). Consumers typically search for information via the Internet but tend to use more traditional channels to order goods (Verhoef et al., 2007). In this context, the customer base cannot be increased through technology alone; since customer confidence is more easily increased through service improvements (Fassnacht and Köse, 2007).

The literature provides numerous models for analyzing the development of e-loyalty, as evidenced by the publication of meta-analyses aimed at summarizing the empirical literature (e.g. Toufaily et al., 2013, Valvi and Fragkos, 2012). Overall, the modeling approaches are diverse, and vary with the context (loyalty to a certain website, retailer, product, or service). The general model we propose to test for different groups of individuals is designed to analyze relationships between online channel characteristics, satisfaction and loyalty in the online shopping environment (e.g. Gounaris et al., 2010). It is a parsimonious model enabling accurate exploration of the effects of unobserved customer heterogeneity on e-loyalty.

The outcome of the customer's encounter with the online retail channel: e-satisfaction and eloyalty

This paper starts from the satisfaction approach used in the model presented by Oliver (1997), which is the most widely used in the literature (Toufaily et al., 2013, Valvi and Fragkos, 2012). According to this model, the individual's level of satisfaction depends on the relationship between the initial expectations and the actual outcome. Customers will be satisfied if the outcome lives up to their expectations. Thus, satisfaction arises from the 
confirmation of expectations, while dissatisfaction ensues from its non-confirmation (Day, 1984, Oliver, 1980).

Jaiswal et al. (2010) define e-satisfaction as follows: "it is an online customer's pleasant/unpleasant sense of fulfillment/non-fulfillment experienced during past transactions at and visits to retailing”. Behavioral intentions are easier to predict with this cumulative conceptualization of satisfaction (Olsen, 2002) than with one relating to a specific transaction (Olsen and Johnson, 2003). Global satisfaction, moreover, is more likely to depend on factors occurring between transactions; that is, factors that tend to be invariable or persistent (e.g., is it easy to shop on the Internet?) than on the specific attributes of a given service experience (e.g., was the price as expected?).

In line with Oliver (1999), we define e-loyalty as a deep commitment towards the online channel for the acquisition of goods and services, taking into account both behavioral and attitudinal loyalty. Behavioral loyalty may simply result from a lack of alternatives, while attitudinal loyalty denotes deeper commitment (Dick and Basu, 1994). The latter is not only a sign of re-purchase intention, but also of resistance to persuasion and adverse expert opinion, and willingness to pay a premium and recommend the channel to others.

As stated earlier, there is evidence to suggest a significant positive relationship between esatisfaction and e-loyalty (Fang et al., 2011, Fassnacht and Köse, 2007, Shankar et al., 2003, Yen and Lu, 2008). Thus, we can expect satisfied Internet shoppers to show more loyalty towards the online channel. This leads to the following hypothesis:

H1: E-loyalty will increase with customer satisfaction.

In e-commerce, satisfaction results from the customer's assessment and impression of the specific characteristics of the online channel, based on cumulative experiences. From the consumer perspective, online shopping cuts information search costs (Citrin et al., 2000), 
provides a wealth of product information (Szymanski and Hise, 2000), and saves time and effort (Doolin et al., 2005, Ha, 2004). When shopping online, therefore, consumers expect a simpler and easier purchase experience (Bridges and Florsheim, 2008). Thus, satisfaction with the online purchase experience will depend on the perceived advantages (Yang and Peterson, 2004). Furthermore, the literature on online consumer behavior finds that these advantages not only influence satisfaction but also enhance future purchase intention (Abdeldayem, 2010).

The relationship between the perceived advantages of the online retail channel, and customer satisfaction and loyalty, evidenced in the above remarks, are captured by the following hypotheses:

H2: The perceived benefits associated with online shopping will have a positive impact on customer satisfaction.

H3: The perceived benefits associated with online shopping will have a positive impact on customer loyalty.

By their very nature, however, some of the characteristics of the online purchase process may actually dissuade customers. It is not possible to touch or test goods prior to purchase (Gupta et al., 2004, McGoldrick and Collins, 2007, Rajamma et al., 2007, Verhoef et al., 2007), acquisition of goods is not immediate (Rohm and Swaminathan, 2004), and the process of returning goods can cause inconvenience (Bower and Maxham, 2012). Thus, the disadvantages of using the online retail channel may be enough to reduce both customer satisfaction and customer loyalty. Therefore, we hypothesize that:

H4: The perceived disadvantages of online shopping will have a negative impact on customer satisfaction.

H5: The perceived disadvantages of online shopping will have a negative impact on customer loyalty. 
Risk is another key component of the online shopping experience. Customers have to give personal and financial data, often to unknown suppliers (De Ruyter et al., 2001, Frambach et al., 2007, Shih, 2004), and consumers have less faith in e-stores than in traditional retail outlets (Lee and Turban, 2001). Thus, perceived risk is a key parameter, especially in the early stages of online channel adoption (De Ruyter et al., 2001, Hsu and Chiu, 2004), and would thus constitute an antecedent of satisfaction and loyalty (Yen, 2010). This leads us to hypothesize that:

H6: Perceived risk will have a negative impact on e-satisfaction.

H7: Perceived risk will have a negative impact on e-loyalty.

In line with the above reasoning, the model to be empirically tested in the online purchase context is shown in Figure 1.

[INSERT FIGURE 1 AROUND HERE]

\section{Heterogeneity in the development of e-loyalty}

Bucklin and Sismeiro (2003) argue that restriction of the analysis to overall customer behavior may lead to erroneous conclusions, given that responses to website stimuli may vary substantially across individuals. A surge in the use of segmentation for the study of online consumer behavior in the pre-purchase and purchase stages has given rise to a wide range of approaches and numerous different segmentation criteria (e.g. Konuş et al., 2008, Rohm and Swaminathan, 2004, Floh et al., 2014).

Research on the post-purchase stage has focused primarily on explaining the outcome variables of the online service encounter, which include satisfaction and loyalty. Thus, less attention has been paid to individual differences in consumer judgments and in the way they develop. 
Table 1 provides a summary from 2002 to the present day of research on e-commerce in which consumer heterogeneity is considered as a factor when exploring the relationship between e-loyalty and its main antecedents. The diverse range of consumer characteristics examined in this research affect relationships between antecedents and satisfaction and loyalty as well as the satisfaction-loyalty relationship itself. Some of the most widely-analyzed variables are product purchase involvement (Castañeda, 2011, Floh and Treiblmaier, 2006, Sanchez-Franco, 2009), the online purchase experience (Casaló et al., 2008, Jaiswal et al., 2010, Khalifa and Liu, 2007), perceived risk (Belanche et al., 2012, Casaló et al., 2008, Currás-Pérez and Sánchez-García, 2012) and inertia (Anderson and Srinivasan, 2003, Anderson and Swaminathan, 2011, Khalifa and Liu, 2007). However, the total number of studies taking these effects into account is quite small.

\section{[INSERT TABLE 1 AROUND HERE]}

The findings emerging from this literature suggest that individual consumer characteristics drive customer satisfaction and loyalty levels, determine the strength of the satisfactionloyalty relationship, and cause the relative importance of the various antecedents to vary, thereby justifying the inclusion of consumer heterogeneity in the study of e-loyalty.

Nevertheless, the empirical evidence accumulated so far remains inconclusive. Firstly, as the data in the table show, since the variables have been studied in isolation, it is impossible to rate their relative importance or study their joint impact. From the methodological perspective, moreover, heterogeneity has largely been captured by a priori segmentation into two groups. A priori segmentation is done using multi-sample analysis, where structural equations estimates of the parameters of the specified model are used to check for betweengroup differences relating to the selected variable.

Authors such as Moore (1980) or Jedidi, Jajpal and DeSarbo (1997) demonstrate that $a$ priori segmentation may be non-viable or inadequate to explain the differences or unobserved 
heterogeneity in customer responses, because only one segmentation criterion is considered in the a priori definition of the segments, and because both the number of segments and the source of the differences are forced. The method therefore incurs the risk of identifying irrelevant segments, which makes it a poor basis for specific market-segmentation, marketpositioning and micro-marketing strategies. A posteriori segmentation, on the other hand, groups individuals according to their responses, thus producing more useful segments for marketing managers (Wedel and Kamakura, 2000).

This paper aims to test the underlying hypothesis of this methodology, namely, that:

H8: Customer loyalty segments in the online retail environment will be different.

\section{Empirical application}

\section{Methodology}

Unlike what happens in a priori segmentation, post hoc methods simultaneously identify the segments and estimate the SEM parameters for each segment. This removes the need to pre-define the segmentation criteria, which emerge a posteriori in order of their capacity to explain the variability in the data (Wedel and Kamakura, 2000). The literature mentions two methodological options. One, which fits into the framework of random parameter models, was proposed by Ansari, Jedidi and Jagpal (2000) for the purposes of structural equations modeling. It is based on the initial assumption that the model parameters are a random variable that varies across individuals according to a given distribution. The other option, the one taken in this paper, involves the use of finite mixture models. The main advantage of this approach over the random parameter option is that it removes the need to specify the underlying function (Chintagunta et al., 1991).

In SEM modelling, Jedidi, Jagpal and Desarbo (1997) develop the general model of mixtures with the twofold purpose of controlling for heterogeneity in the data and obtaining 
behaviorally-distinct segments within the general pattern. This general model is the same as for the case in which the parameters are invariant between groups (Joreskog, 1973) with the particularity that the latent variables, the observed variables and the measurement errors, and therefore, also, the parameters to be estimated, are segment-specific. Firstly, the number of segments, G, is usually taken as given and the parameters are estimated by maximum likelihood using the EM algorithm. The numbers of segments and parameter vectors, which can vary freely between segments, are set in accordance with the a priori known data about the issue under investigation and the goodness-of-fit between the models and the data. Because conventional goodness-of-fit statistics based on the likelihood ratio prove inadequate in this context, global goodness-of-fit indices, such as the AIC, the CAIC or the BIC are required. Using simulation techniques, Jedidi, Jagpal and Desarbo (1997) showed the BIC and AIC criteria to be the best means of detecting the number of underlying segments.

\section{The Sample}

The target population for this study consisted of online shoppers in Spain. A sample of 1,200 online shoppers was selected using sex and age quotas based on data from a survey of household ICT adoption and usage conducted by the Spanish National Institute for Statistics in 2009. The data were collected by means of an online questionnaire designed by a market research company and administered by means of a technique known as computer-assisted web interviewing (CAWI).

The data collection and database screening process provided 972 valid cases. Some descriptive statistics are given in Table 2. The average age of the interviewees is $36.56 .80 \%$ are males. 58.3\% have no children. Approximately 57\% are educated up to university level or higher. $38 \%$ have a secondary education and the rest primary or none. $24 \%$ reside in municipalities with fewer than 20,000 inhabitants and almost 29\% in cities with 500,000 
inhabitants or more. $21 \%$ have a monthly income of less than $1000 €, 25.51 \%$ a monthly income of $1,500 €$ and $35 \%$ a monthly income of $1,500 €$ or more.

\section{[INSERT TABLE 2 AROUND HERE]}

\section{Measurement of the variables}

The online questionnaire is divided into different sections to address the various objectives of the study. The first section deals with aspects of Internet purchase behavior, such as frequency of online purchase, measured as the number of products purchased and Internet purchases as a percentage of total purchases, in four product categories (T-shirts, books, airline tickets and electronic goods). Four product categories are included in order to control for potential variation in product involvement levels and the ability to access Internet information, which can lead to different purchase habits (Chocarro et al., 2013).

The second section, which focuses on individual shopping styles, collects data such as quality and price awareness, innovation, inertia and shopping enjoyment. The 0 to 10 -point Likert scales used to measure these items are adaptations of those used by Ailawadi et al.(2001), Konus et al.(2008) and Lichtenstein et al.(1990).

The third section explores attitudes towards online shopping, using a combination of indicators taken from Brengman et al. (2005) and Smith and Swinyard (2001). Interpretation of these attitudes is based on interviewees' perceptions of the three aspects of online shopping mentioned in our conceptual framework: advantages, disadvantages and risks.

Customer satisfaction with online shopping is measured with a single indicator, while loyalty, in both its behavioral and attitudinal dimensions, is measured using three Likert-type scale indicators (Zeithaml et al., 1996). The last part of the questionnaire collects the sociodemographic data already mentioned (age, sex, level of education, number of children, size of place of residence and income). 
In order to assess the quality of the multi-item scales, we checked them for unidimensionality, convergent validity, reliability and discriminant validity. Thus, we confirmed the psychometric properties of the multi-item scales used to measure the variables included in the empirical model (Figure 1) and those of the multi-item scales used to measure different shopping styles, that is, the variables used to define the shopper segment profiles detected. The results of these checks, which are shown in Appendix1, confirm the unidimensionality, validity and reliability of the measuring scales. The final items for each scale are shown in Appendix2.

\section{Results}

The aggregate analysis

The first results to be presented are for the aggregate analysis, in which the presence of heterogeneity was not considered (see Table 3).

As can be seen, the estimated model fits the data well. As expected, the level of customer satisfaction has a positive and significant impact on e-loyalty, thus confirming hypothesis 1 . Similarly, the perceived advantages of online shopping have a positive influence on esatisfaction (hypothesis 2) and loyalty (hypothesis 3).

\section{[INSERT TABLE 3 AROUND HERE]}

The findings also show, in opposition with the above, that the perceived disadvantages of online shopping have a significant negative impact on e-loyalty and that the perceived risks affect both e-satisfaction and e-loyalty, thus enabling us to confirm hypotheses 5, 6 and 7, respectively. However, although the impact of perceived disadvantages on e-satisfaction are of the expected (negative) sign, their lack of significance means that we can neither confirm nor reject hypothesis 4 . 


\section{Segmentation}

This initial model was then re-estimated taking the possible presence of heterogeneity into account and using the same free parameters as in the structural equations model. This analysis also allowed for between-segment differences in the variance of the latent response variables. The results of the procedure described in the methodology section are given in Table 4, which also shows the number of categories used in the estimation of each model (column 1); whether differences in the variance are allowed (column 2); the log likelihood function (column 3); the goodness-of-fit indices: AIC (column 4), BIC (column 5), and adjusted BIC (column 6) (Jedidi et al., 1997); the percentage of observations per category in each model (column 7); and the number of parameters to be estimated (column 8).

As can be seen, the goodness-of-fit of the aggregate model in which heterogeneity is not considered (M1) is clearly inferior to that of any of the models that include some degree of control for this heterogeneity.

Thus, in relation to our first objective, we are able to confirm the presence of heterogeneity in the online satisfaction and online loyalty development process.

\section{[INSERT TABLE 4 AROUND HERE]}

Of all the estimated models, the best fit, according to the BIC and SBIC values, is achieved by the final model, where there are three classes with free variance between classes (rowM5). The AIC value shows the best-fitting model to be the one with four classes and free variance (M7). Faced with this discrepancy between goodness-of-fit criteria, we are motivated by the fact that the last class in the four-class model contains only 5\% of the subjects to select the more parsimonious three-class model, where segmentation divides the sample into three groups representing 58\%, $30 \%$ and $12 \%$ of the data, respectively. 
Table 5 offers a comparison between the results of the aggregate model and the solution for each segment, and Table 6 gives the descriptive statistics of the model variables for each segment. The combined data in these two tables show the segments to be both mutually distinct and different from the aggregate model, indicating that significant biases are incurred in analyses of e-satisfaction and e- loyalty development processes in which the possible presence of latent market segments is not considered. This enables us to confirm hypothesis 8. [INSERT TABLE 5 AROUND HERE]

Class 1 , which represents $58 \%$ of the total sample, is the largest segment. It shows not only higher average satisfaction and loyalty levels but also less within-group variance than classes 2 and 3. The online shoppers belonging to this group are therefore much more satisfied with online shopping than those of the other two groups and show a higher degree of loyalty towards it.

\section{[INSERT TABLE 6 AROUND HERE]}

E-loyalty in this group of shoppers does not depend on their level of satisfaction with online shopping (Hypothesis 1). Their e-satisfaction and e-loyalty are significantly influenced by their perceptions of the advantages of online shopping (Hypotheses 2 and 3, respectively). Its disadvantages do not significantly influence either satisfaction or loyalty in this group (Hypotheses 4 and 5). The only significant parameter estimate is for the impact of perceived risks on satisfaction (Hypothesis 6), although its value is much smaller than that of the estimated impact of the advantages of online shopping. This model has greater explanatory capacity for this segment than for the other two and also more predictive power for e-loyalty than that provided by the general model. 
Thus, both the valuation of the advantages of online shopping and the influence of these advantages on satisfaction and loyalty are highest in this segment. This leads us to label the individuals in class 1 as optimists with respect to online shopping.

The middle-sized segment, representing $30 \%$ of the total sample, is class 2 . It is characterized by a not very high level of satisfaction ranging around the midpoint, that is, slightly higher than that of class 3 but lower than that of class 1. It also shows low loyalty levels, especially in comparison with class1.

In this segment also, e-satisfaction does not contribute to e-loyalty (Hypothesis 1). The advantages of online shopping have a significant impact on e-satisfaction (Hypothesis 2) and on e-loyalty (Hypothesis 3). It is also worth noting that this is the only segment in which the disadvantages of online shopping have a significant impact on e-satisfaction (Hypothesis 4), which is something that is not observed even in the aggregate model. At a significance level of $10 \%$, the disadvantages of online shopping have a direct impact on e-loyalty (Hypothesis 5). The perceived risk of online shopping does not have a significant impact on either satisfaction or loyalty. It is also worth noting that, in the development of e-satisfaction, the impact of the advantages slightly outweighs that of the disadvantages; whereas, in the development of e-loyalty, the impact is similar. Finally, this model has less explanatory power overall than the general model and for classes 1 and 3. Based on these results, we label the individuals grouped in class 2 as "pessimists” with respect to online shopping.

The last group of consumers, that is, class 3 , accounts for $12 \%$ of the online shopper sample. This is the group with the lowest averages on all the characteristics of online shopping, that is, all the variables included in advantages, disadvantages, and risks. The individuals within this group show the lowest average e-satisfaction levels, along with rather low e-loyalty (around the 4-point level). In terms of significant relationships, this is the only segment in which e-satisfaction has a direct impact one-loyalty (Hypothesis 1). As in the 
previous classes, the perceived advantages of online shopping have a significant impact on esatisfaction (Hypothesis 2); but only an indirect impact on e-loyalty through e-satisfaction (0.44) (Hypothesis 3). The disadvantages of online shopping also have an impact on the development of e-loyalty (Hypothesis 5). Lastly, it should be noted that, of the three antecedents of e-loyalty, e-satisfaction is the most influential, followed by perceived disadvantages. In class 3, moreover, the explanatory power of the models is higher for eloyalty than in the first two classes, while, for e-satisfaction, it is lower than in class 1 , and higher than in class 2 . We label the individuals grouped in class 3, therefore, as neutral with respect to online shopping.

\section{Characteristics of online shoppers per segment}

Knowledge of the shopper profile in each segment enables differentiated online satisfaction and online loyalty management.

To complete the post-hoc segmentation, therefore, we need to determine which characteristics describe each of the revealed classes. We do this by analyzing the probability of belonging to one class or another by means of a logit regression, in which, for each segment, the probability of belonging is explained in terms of socio-demographic characteristics (age, sex, number of children, level of education, monthly income, and size of place of residence) and shopping-style characteristics (quality awareness, innovativeness, shopping enjoyment, price awareness, inertia, and multi-channel shopping behavior).Three models are estimated, in each case taking one segment as the reference against which to compare the other two. For the sake of simplicity, in addition to the model parameters, which show which differences are significant, Table 8 also shows the descriptive statistics of the variables within each class.

\section{[INSERT TABLE 7 AROUND HERE]}


As Table 7 shows, differences can be observed between class 1 and classes 2 and 3, and between class 2 and class 3 . The online shoppers in class 1 (optimists) have the highest proportion of men, and a higher proportion of university-educated and high-income individuals. Their psychographic characteristics show that they rank the highest in innovativeness for trying new products, and in shopping enjoyment, and also have a high level of price awareness. These characteristics are consistent with the important role played by the perceived advantages of online shopping in the development of e-satisfaction and eloyalty, since it is precisely these advantages that enable compatibility between price awareness and shopping enjoyment, through, say, price comparison sites and multiple website visits.

Class 2 has the highest proportion of females, the highest average age, and the highest average number of children, but shows lower average income than the other two classes. This group (labeled “pessimists”) reports, as expected, the lowest online shopping frequency, in association with a higher perception of the disadvantages and risks of online shopping. The psychographic characteristics of the individuals in this class show that they rank the lowest in innovativeness, in consistency with their online purchase patterns, and have higher levels of inertia and quality awareness.

The individuals in class 3, labeled "neutral”, report the highest online shopping frequency, and therefore need to make a fuller assessment of online channel capabilities before giving their satisfaction and loyalty ratings. This class is the youngest on average and has the highest proportion of non-city dwellers. We are unable to provide a precise description of their shopping style, however, because they show the lowest levels of quality awareness, shopping enjoyment, price awareness, and inertia. The limited product offer in less populated places of residence and the higher exposure of young people to the online channel are two factors that 
might explain how their high levels of online shopping frequency can coincide with such low e-satisfaction levels.

\section{Discussion and management implications}

This study highlights the need to consider unobserved customer heterogeneity when attempting to explain satisfaction and loyalty development processes in the retail context in general, and e-commerce in particular.

When using structural equations models of latent segmentation, there is no need for predefined segmentation criteria, because the segmentation is based on inter-personal heterogeneity with respect to the modeled relationships. To our knowledge, this is the first time this approach has been used to analyze the impact of customer heterogeneity on esatisfaction and e-loyalty.

Our first objective, which was to test the applicability of post-hoc segmentation models to the e-loyalty development process, has been satisfactorily fulfilled, since the analysis has enabled us to identify three distinct segments among on-line service consumers.

Our second objective was to evaluate biases resulting from the above-mentioned unobserved heterogeneity. Comparison of the aggregate model with those used for the distinct segments reveals significant differences. Firstly, the link between satisfaction and loyalty is not homogeneous across all e-shoppers. A direct relationship between the two is found in only one of the three detected segments, and cannot be confirmed in the other two. We are able to conclude that satisfaction is a pre-requisite of e-loyalty, but is not sufficient to increase it in all e-shoppers. This finding is consistent with previous research showing that personal characteristics have a moderating impact on the satisfaction-loyalty relationship (e.g. Belanche et al., 2012, Souitaris and Balabanis, 2007, Anderson and Srinivasan, 2003). The aggregate model underestimates the role of satisfaction in one of the segments, and 
overestimates it in the other two. As far as online channel characteristics are concerned, the advantages are the main determinant of satisfaction and loyalty, followed by the risks and disadvantages in the aggregate model. This indicates the order of priority for retailers' efforts to increase customer satisfaction and loyalty levels. Due to consumer heterogeneity, however, the relative importance of the perceived advantages, disadvantages and risks varies between segments. To maximize value from the online channel, therefore, retailers need to tailor their marketing stimuli to their website target segment.

Our third and fourth objectives were closely related. First, we aimed to analyze the various segments, and then, to describe them in an identifiable and actionable fashion. Three distinct segments are detected. The first, which we label "optimists" (58\% of the sample), contains a higher proportion of males, and individuals with higher income and education levels. The members of this segment are innovative and enjoy online shopping and price comparison. The highest levels of e-satisfaction and e-loyalty are found in this segment. The main determinant of their loyalty level lies in the perceived advantages of the online channel, while their level of satisfaction is determined by the perceived advantages in combination with the perceived risks. In order to increase the loyalty of this customer segment, e-retailers need to invest money and effort into enhancing the advantages by simplifying the online shopping process, and enhancing the on-line shopping experience. If this is to be achieved, the virtual store needs to be attractive and functional in design, and steps-to-purchase reduced to a minimum. In addition, website design must be adjusted to different screen formats to match the wide range of devices used to surf the Internet. When it comes to increasing customer satisfaction, risk-reduction strategies will help to enhance the advantages. Online retailers have several options to help them in this respect. One is to avoid compulsory pre-purchase registration, which many customers resent because it is not required in a physical store. Another is to avoid asking for unnecessary data when the purchase process is almost complete, and to give 
a convincing reason for requesting certain information (such as a telephone number). Lastly, the customer needs to be reassured about the safety and reliability of the shopping environment through coherent web design, a Secure Socket Layer protocol to ensure the security of the transaction, the retailer's compliance with payment card sector data security standards, and an indication of the number of service users online.

The second segment of consumers, the "pessimists", accounts for $30 \%$ of the sample and includes a higher proportion of older women. They report the lowest online purchase frequency along with the highest levels of inertia and quality awareness and relatively low innovativeness. In line with Anderson and Srinivasan (2003), higher inertia is found to erode the link between satisfaction and loyalty in this segment. Its members are satisfied with the channel, but their future usage intention is low, due, mainly, to their perception of its disadvantages. They perceive the main disadvantage to be the inconvenience of returning goods, followed by the impossibility of checking the sensory qualities of the product prior to consumption. To remove the inconvenience associated with returning goods purchased online, the e-retailer should offer the customer several goods return points (their own physical store, should it exist; physical establishments with which the e-retailer has an agreement; the customer's own home, the post office, etc.). To overcome the problem of product intangibility in Internet shopping, a clear description of product characteristics is vital. E-retailers should therefore provide a detailed description of all product components, accompanied with photos, opinions of previous buyers and expert reports.

The third segment, which is the smallest, (12\% of the sample) is labeled "neutral”. This is the youngest segment and has the highest online purchase frequency. It has the lowest proportion of city-dwellers and its members give the least importance to the various advantages, disadvantages and risks attached to online shopping. There is a strong link between satisfaction and loyalty in this segment and there is plenty of room to improve their 
satisfaction and loyalty levels, which are low on average. Online retailers can increase the satisfaction and, indirectly, the loyalty of these customers by working on the advantages of online shopping, while strategies aimed at reducing the disadvantages will have a direct impact on future purchase intention.

Among the shortcomings of this study is that the model is designed to explore only linear relationships, when there might also be non-linear relationships, or thresholds or interaction effects in the relationship between service features and customer satisfaction and loyalty development. SEM models of latent segmentation require the estimation of a much larger number of parameters than estimated in the parsimonious model selected for this study, but would undoubtedly produce a richer characterization of the segments. Another limitation of this paper is that it measures the variables for online retailers in general, unlike other studies, which focus on one in particular. While this enriches the analysis, because the findings can be extrapolated to different contexts, it also means that the measuring scales are less precise because they need to fit four different product categories (books, T-shirts, electronic goods, and airline tickets). To validate our conclusions, therefore, it would be useful to conduct this analysis on e-retailers of a specific type of goods (search goods, experience goods, services, etc.). There remains one last shortcoming of our study design, which involves some of the measuring scales. Satisfaction, for instance, is measured by means of a single indicator of global satisfaction with online shopping experiences, which means that we are unable to control for measurement error.

\section{References}

Abdeldayem, M.M. (2010), "A study of customer satisfaction with online shopping: evidence from the UAE", International Journal of Advanced Media and Communication, vol. 4, no. 3, pp. 235-257. 
Agrawal, V., Arjona, L.D. and Lemmens, R. (2001), "E-performance: The path to rational exuberance", The McKinsey Quarterly, vol. 1, pp. 31-43.

Ailawadi, K.L., Neslin, S.A. and Gedenk, K. (2001), "Pursuing the value-conscious consumer: store brands versus national brand promotions", Journal of Marketing, vol. 65, no. 1, pp. 71-89.

Anderson, E.W. and Mittal, V. (2000), "Strengthening the satisfaction-profit chain", Journal of Service Research, vol. 3, no. 2, pp. 107-120.

Anderson, J.C. and Gerbing, D.W. (1988), "Structural equation modeling in practice: A review and recommended two-step approach.", Psychological Bulletin, vol. 103, no. 3, pp. 411.

Anderson, R.E. and Srinivasan, S.S. (2003), "E-satisfaction and e-loyalty: A contingency framework", Psychology \& Marketing, vol. 20, no. 2, pp. 123-138.

Anderson, R.E. and Swaminathan, S. (2011), "Customer satisfaction and loyalty in e-markets: A PLS path modeling approach", The Journal of Marketing Theory and Practice, vol. 19, no. 2, pp. 221-234.

Ansari, A., Jedidi, K. and Jagpal, S. (2000), "A hierarchical Bayesian methodology for treating heterogeneity in structural equation models", Marketing Science, vol. 19, no. 4, pp. $328-347$

Bagozzi, R.P. and Yi, Y. (1988), "On the evaluation of structural equation models", Journal of the Academy of Marketing Science, vol. 16, no. 1, pp. 74-94.

Bagozzi, R.P. and Baumgartner, H. (1994). "The evaluation of structural models and hypothesis testing". Bagozzi, R., Priciples of Marketing Research, Blackwell, Cambridge, 402. 
Balabanis, G., Reynolds, N. and Simintiras, A. (2006), "Bases of e-store loyalty: Perceived switching barriers and satisfaction", Journal of Business Research, vol. 59, no. 2, pp. 214224.

Belanche, D., Casaló, L.V. and Guinalíu, M. (2012), "Website usability, consumer satisfaction and the intention to use a website: the moderating effect of perceived risk", Journal of Retailing and Consumer Services, vol. 19, no. 1, pp. 124-132.

Bower, A.B. and Maxham, J.G. (2012), "Return shipping policies of online retailers: Normative assumptions and the long-term consequences of fee and free returns", Journal of Marketing, vol. 76, no. 5, pp. 110-124.

Brengman, M., Geuens, M., Weijters, B., Smith, S.M. and winyard, W.R. (2005), "Segmenting Internet shoppers based on their Web-usage-related lifestyle: a cross-cultural validation", Journal of Business Research, vol. 58, no. 1, pp. 79-88.

Bressolles, G., Durrieu, F. and Senecal, S. (2014), "A consumer typology based on e-service quality and e-satisfaction", Journal of Retailing and Consumer Services, vol. 21, no. 6, pp. 889-896.

Bridges, E. and Florsheim, R. (2008), "Hedonic and utilitarian shopping goals: the online experience", Journal of Business Research, vol. 61, no. 4, pp. 309-314.

Bucklin, R.E. and Sismeiro, C. (2003), "A model of web site browsing behavior estimated on clickstream data", Journal of Marketing Research, vol. 40, no. 3, pp. 249-267.

Casaló, L.V., Flavián, C. and Guinalíu, M. (2008), "The role of satisfaction and website usability in developing customer loyalty and positive word-of-mouth in the e-banking services", International Journal of Bank Marketing, vol. 26, no. 6, pp. 399-417.

Castañeda, J.A. (2011), "Relationship between customer satisfaction and loyalty on the internet", Journal of Business and Psychology, vol. 26, no. 3, pp. 371-383. 
Chintagunta, P.K., Jain, D.C. and Vilcassim, N.J. (1991), "Investigating Heterogeneity in Brand Preferences in Logit Models for Panel Data.", Journal of Marketing Research (JMR), vol. 28, no. 4.

Chocarro, R., Cortiñas, M. and Villanueva, M. (2013), "Situational variables in online versus offline channel choice", Electronic Commerce Research and Applications, vol. 12, no. 5, pp. 347-361.

Citrin, A.V., Sprott, D.E., Silverman, S.N. and Stem Jr, D.E. (2000), "Adoption of internet shopping: the role of consumer innovativeness", Industrial Management \& Data Systems, vol. 100, no. 7, pp. 294-300.

Currás-Pérez, R. and Sánchez-García, I. (2012), "Satisfaction and Loyalty to a Website: The Moderating Effect of Perceived Risk", Esic-Market Economic and Business Journal, vol. 141, pp. 183-207.

Day, R.L. (1984), "Modeling choices among alternative responses to dissatisfaction.", Advances in Consumer Research, vol. 11, no. 1.

De Ruyter, K., Wetzels, M. and Kleijnen, M. (2001), "Customer adoption of e-service: an experimental study", International Journal of Service Industry Management, vol. 12, no. 2, pp. 184-207.

Dick, A.S. and Basu, K. (1994), "Customer loyalty: toward an integrated conceptual framework", Journal of the Academy of Marketing Science, vol. 22, no. 2, pp. 99-113.

Doolin, B., Dillon, S., Thompson, F. and Corner, J.L. (2005), "Perceived risk, the Internet shopping experience and online purchasing behavior: A New Zealand perspective", Journal of Global Information Management (JGIM), vol. 13, no. 2, pp. 66-88.

Dusto, A. 2013, October 30, 2013-last update, 60\% of U.S. retail sales will involve the web by 2017 [Homepage of http://www.internetretailer.com/], [Online]. Available: http://www.internetretailer.com/2013/10/30/60-us-retail-sales-will-involve-web-2017 [2014, . 
Fang, Y., Chiu, C. and Wang, E.T. (2011), "Understanding customers' satisfaction and repurchase intentions: An integration of IS success model, trust, and justice", Internet Research, vol. 21, no. 4, pp. 479-503.

Fassnacht, M. and Köse, I. (2007), "Consequences of Web-based service quality: Uncovering a multi-faceted chain of effects", Journal of Interactive Marketing, vol. 21, no. 3, pp. 35-54.

Floh, A. and Treiblmaier, H. (2006), "What keeps the e-banking customer loyal? A multigroup analysis of the moderating role of consumer characteristics on e-loyalty in the financial service industry." Journal of Electronic Commerce Research, vol. 7, no. 2.

Floh, A., Zauner, A., Koller, M. and Rusch, T. (2014), "Customer segmentation using unobserved heterogeneity in the perceived-value-loyalty-intentions link", Journal of Business Research, vol. 67, no. 5, pp. 974-982.

Fornell, C. and Larcker, D.F. (1981), "Evaluating structural equation models with unobservable variables and measurement error", Journal of Marketing Research, vol. 18, no. 1, pp. 39-50.

Frambach, R.T., Roest, H.C.A. and Krishnan, T.V. (2007), "The impact of consumer internet experience on channel preference and usage intentions across the different stages of the buying process", Journal of Interactive Marketing, vol. 21, no. 2, pp. 26-41.

Gensler, S., Leeflang, P. and Skiera, B. (2012), "Impact of online channel use on customer revenues and costs to serve: Considering product portfolios and self-selection", International Journal of Research in Marketing, vol. 29, no. 2, pp. 192-201.

Gounaris, S., Dimitriadis, S. and Stathakopoulos, V. (2010), "An examination of the effects of service quality and satisfaction on customers' behavioral intentions in e-shopping", Journal of Services Marketing, vol. 24, no. 2, pp. 142-156. 
Gupta, A., Su, B.-. and Walter, Z. (2004), "An empirical study of consumer switching from traditional to electronic channels: A purchase-decision process perspective", International Journal of Electronic Commerce, vol. 8, no. 3, pp. 131-161.

Ha, H. (2004), "Factors affecting online relationships and impacts", The Marketing Review, vol. 4, no. 2, pp. 189-209.

Hsu, M. and Chiu, C. (2004), "Predicting electronic service continuance with a decomposed theory of planned behaviour", Behaviour \& Information Technology, vol. 23, no. 5, pp. 359373.

Jaiswal, A.K., Niraj, R. and Venugopal, P. (2010), "Context-general and context-specific determinants of online satisfaction and loyalty for commerce and content sites", Journal of Interactive Marketing, vol. 24, no. 3, pp. 222-238.

Jedidi, K., Jagpal, H.S. and DeSarbo, W.S. (1997), "Finite-mixture structural equation models for response-based segmentation and unobserved heterogeneity", Marketing Science, vol. 16, no. 1, pp. 39-59.

Joreskog, K.G. (1973), "A general method for estimating a linear structural equation system.",Structural Equation Models in the Social Science, vol. 2, pp. 85-102.

Khalifa, M. and Liu, V. (2007), "Online consumer retention: contingent effects of online shopping habit and online shopping experience", European Journal of Information Systems, vol. 16, no. 6, pp. 780-792.

Kim, J., Jin, B. and Swinney, J.L. (2009), "The role of etail quality, e-satisfaction and e-trust in online loyalty development process", Journal of Retailing and Consumer Services, vol. 16, no. 4, pp. 239-247.

Konuş, U., Verhoef, P.C. and Neslin, S.A. (2008), "Multichannel shopper segments and their covariates", Journal of Retailing, vol. 84, no. 4, pp. 398-413. 
Lahuerta Otero, E., Muñoz Gallego, P.A. and Pratt, R.M. (2014), "Click-and-Mortar SMEs: Attracting customers to your website", Business Horizons .

Lee, M.K. and Turban, E. (2001), "A trust model for consumer internet shopping", International Journal of Electronic Commerce, vol. 6, pp. 75-92.

Lichtenstein, D.R., Netemeyer, R.G. and Burton, S. (1990), "Distinguishing coupon proneness from value consciousness: an acquisition-transaction utility theory perspective", The Journal of Marketing, vol. 54, pp. 54-67.

Lin, C. and Kuo, B.Z. (2013), "Escalation of Loyalty and the Decreasing Impact of Perceived Value and Satisfaction over Time", Journal of Electronic Commerce Research, vol. 14, no. 4. McGoldrick, P.J. and Collins, N. (2007), "Multichannel retailing: profiling the multichannel shopper", International Review of Retail, Distribution and Consumer Research, vol. 17, no. 2, pp. 139-158.

Moore, W.L. (1980), "Levels of Aggregation in Conjoint Analysis: An Empirical Comparison.", Journal of Marketing Research (JMR), vol. 17, no. 4.

Oliver, R.L. (1999), "Whence consumer loyalty?", Journal of Marketing, vol. 63, no. 4.

Oliver, R.L. (1997), "Satisfaction: A behavioral perspective on the customer", New York, .

Oliver, R.L. (1980), "A cognitive model of the antecedents and consequences of satisfaction decisions", Journal of Marketing Research, , pp. 460-469.

Olsen, L.L. and Johnson, M.D. (2003), "Service equity, satisfaction, and loyalty: from transaction-specific to cumulative evaluations", Journal of Service Research, vol. 5, no. 3, pp. 184-195.

Olsen, S.O. (2002), "Comparative evaluation and the relationship between quality, satisfaction, and repurchase loyalty", Journal of the Academy of Marketing Science, vol. 30, no. 3, pp. 240-249. 
Rajamma, R.K., Paswan, A.K. and Ganesh, G. (2007), "Services purchased at brick and mortar versus online stores, and shopping motivation", Journal of Services Marketing, vol. 21, no. 3, pp. 200-212.

Reichheld, F.F., Markey Jr, R.G. and Hopton, C. (2000), "The loyalty effect-the relationship between loyalty and profits", European Business Journal, vol. 12, no. 3, pp. 134-139.

Reichheld, F.F. and Schefter, P. (2000), "E-loyalty", Harvard Business Review, vol. 78, no. 4, pp. 105-113.

Rohm, A.J. and Swaminathan, V. (2004), "A typology of online shoppers based on shopping motivations", Journal of Business Research, vol. 57, no. 7, pp. 748-757.

Sanchez-Franco, M.J. (2009), "The moderating effects of involvement on the relationships between satisfaction, trust and commitment in e-banking", Journal of Interactive Marketing, vol. 23, no. 3, pp. 247-258.

Shankar, V., Smith, A.K. and Rangaswamy, A. (2003), "Customer satisfaction and loyalty in online and offline environments", International Journal of Research in Marketing, vol. 20, no. 2, pp. 153-175.

Shih, H. (2004), "An empirical study on predicting user acceptance of e-shopping on the Web", Information \& Management, vol. 41, no. 3, pp. 351-368.

Smith, S. and Swinyard, W. (2001),"The identification of shopping behaviors among Internet users", paper presented at Cardiff Business School, World Marketing Congress.

Souitaris, V. and Balabanis, G. (2007), "Tailoring online retail strategies to increase customer satisfaction and loyalty", Long Range Planning, vol. 40, no. 2, pp. 244-261.

Srinivasan, S.S., Anderson, R. and Ponnavolu, K. (2002), "Customer loyalty in e-commerce: an exploration of its antecedents and consequences", Journal of Retailing, vol. 78, no. 1, pp. 41-50. 
Szymanski, D.M. and Hise, R.T. (2000), "E-satisfaction: an initial examination", Journal of Retailing, vol. 76, no. 3, pp. 309-322.

Toufaily, E., Ricard, L. and Perrien, J. (2013), "Customer loyalty to a commercial website: Descriptive meta-analysis of the empirical literature and proposal of an integrative model", Journal of Business Research, vol. 66, no. 9, pp. 1436-1447.

Valvi, A.C. and Fragkos, K.C. (2012), "Critical review of the e-loyalty literature: a purchasecentred framework", Electronic Commerce Research, vol. 12, no. 3, pp. 331-378.

Verhoef, P.C., Neslin, S.A. and Vroomen, B. (2007), "Multichannel customer management: Understanding the research-shopper phenomenon", International Journal of Research in Marketing, vol. 24, no. 2, pp. 129-148.

Wedel, M. \& Kamakura, W. 2000, Market segmentation: Conceptual and methodological foundations, Springer.

Yadav, M.S. and Pavlou, P.A. (2014), "Marketing in Computer-Mediated Environments: Research Synthesis and New Directions", Journal of Marketing, vol. 78, no. 1, pp. 20-40.

Yang, Z. and Peterson, R.T. (2004), "Customer perceived value, satisfaction, and loyalty: the role of switching costs", Psychology \& Marketing, vol. 21, no. 10, pp. 799-822.

Yen, C. and Lu, H. (2008), "Factors influencing online auction repurchase intention", Internet Research, vol. 18, no. 1, pp. 7-25.

Yen, Y. (2010), "Can perceived risks affect the relationship of switching costs and customer loyalty in e-commerce?", Internet Research, vol. 20, no. 2, pp. 210-224.

Zeithaml, V.A., Berry, L.L. and Parasuraman, A. (1996), "The behavioral consequences of service quality.", Journal of Marketing, vol. 60, no. 2, pp. 31-46.

Zhang, Y., Fang, Y., Wei, K., Ramsey, E., McCole, P. and Chen, H. (2011), "Repurchase intention in B2C e-commerce. A relationship quality perspective", Information \& Management, vol. 48, no. 6, pp. 192-200. 